\title{
The Forex Market in Practice: A Computing Approach for Automated Trading Strategies
}

\section{Crescenzio Gallo*}

Department of Clinical and Experimental Medicine University of Foggia Viale Luigi Pinto 1, 71122 Foggia, Italy

*Corresponding author: Crescenzio Gallo, Department of Clinical and Experimental Medicine University of Foggia Viale Luigi Pinto 1 , 71122 Foggia, Italy, Tel: +39 0881-588067; E-mail: crescenzio.gallo@unifg.it

Received date: June 11, 2014; Accepted date: July 10, 2014; Published date: July 20, 2014

Copyright: ( 2014 Gallo C. This is an open-access article distributed under the terms of the Creative Commons Attribution License, which permits unrestricted use, distribution, and reproduction in any medium, provided the original author and source are credited

\begin{abstract}
Prediction of various market indicators is an important issue in finance. This can be accomplished through computer models and related applications. It turned out that artificial models have both great advantages and some limitations for learning the data patterns and predicting future values of the financial phenomenon under analysis. In this paper we analyze the particular financial market called Forex and the way computing models are used to automate trading strategies by making affordable predictions on the evolution of exchange rates between currencies.
\end{abstract}

Keywords: Forex; Finance; Computing model

\section{What is Forex: A Definition}

The Foreign Currency Exchange Market (Forex, FX, or currency market) is a decentralized financial exchange market, distributed worldwide and deregulated, for trading spot currencies. The Forex is a "de facto" market without a physical exchange center or a group of official rules, although the accepted "default" rules are simple, clear and consistent with the brokers and banks [1]. It is open from 20:15 UTC to 22:00 UTC Sunday on Friday, 24 hours a day. This capability is called OTC, Over The Counter.

Trade in the Forex are made by buying or selling a quantity of currency "against" another. The exchange rates [2] are all included in a table with three columns (Figure 1): one for the pair of currencies that can be exchanged (for example USD/EUR), one for the buying rate and the third for the sale. This table is updated about each second. The time base of the Forex is in fact the tick, which usually corresponds to a second; but in case of crowding of trading, for which brokers are unable to synchronize quickly between them, this time interval is lengthened [3].

The major currencies are USD (U.S. Dollar), EUR (Euro), GBP (British Pound), YEN (Japanese Yen) and CHF (Swiss Franc). From these are obtained the 10 major trading pairs, which become 24 if one includes the currencies CAD (Canadian Dollar), AUS (Australian Dollar) and NZD (New Zealand Dollar). Depending on your broker you can operate on more Forex pairs that include, for example, the Singapore Dollar SGD, the Hong Kong Dollar HKD and the Danish Krone DKK.

A typical operation on these cross-currencies can be made for purchase or sale regardless of the base currency of the trading account. So it is important to have in mind from the outset that in Forex you can work at any time, provided you know what do. This is to emphasize the basic difference compared to the best known stock market financial field where you can sell only after buying and you can plan a successful transition only if a stock can be bought cheaply and then resold after its value has increased.

\begin{tabular}{|c|c|c|}
\hline Symbol & Offer & Request \\
\hline \USD-CHF & 1.06563 & 1.06603 \\
\hline † GBP-USD & 1.53687 & 1.53715 \\
\hline$\downarrow$ USD-JPY & 93.164 & 93.194 \\
\hline$\uparrow$ EUR-USD & 1.34981 & 1.35001 \\
\hline ^AUD-USD & 0.93291 & 0.93321 \\
\hline$\uparrow$ USD-CAD & 1.00238 & 1.00294 \\
\hline † EUR-GBP & 0.87817 & 0.87844 \\
\hline$\uparrow$ EUR-CHF & 1.43856 & 1.43895 \\
\hline † EUR-JPY & 125.753 & 125.813 \\
\hline$\downarrow$ GBP-JPY & 143.174 & 143.229 \\
\hline † GBP-CHF & 1.63784 & 1.63849 \\
\hline$\uparrow$ EUR-CAD & 1.35312 & 1.35400 \\
\hline$\uparrow$ EUR-AUD & 1.44645 & 1.44715 \\
\hline \USD-SGD & 1.36930 & 1.39030 \\
\hline † NZD-USD & 0.71566 & 0.71656 \\
\hline$\downarrow$ CHF-JPY & 87.395 & 87.455 \\
\hline$\downarrow$ EUR-NZD & 1.88382 & 1.88582 \\
\hline$\downarrow$ AUD-JPY & 86.917 & 86.969 \\
\hline$\downarrow$ AUD-NZD & 1.30180 & 1.30379 \\
\hline$\uparrow$ AUD-CAD & 0.93522 & 0.93592 \\
\hline$\uparrow$ AUD-CHF & 0.99409 & 0.99479 \\
\hline$\Downarrow$ CAD-CHF & 1.06258 & 1.06338 \\
\hline$\Downarrow$ CAD-JPY & 92.892 & 92.972 \\
\hline ^NZD-JPY & 66.678 & 66.778 \\
\hline$\downarrow$ USD-CKK & 5.51289 & 5.51439 \\
\hline \USD-NCK & 5.90070 & 5.90710 \\
\hline \USD-SEK & 7.19538 & 7.20336 \\
\hline$\downarrow$ SGD-JPY & 67.014 & 67.064 \\
\hline$\downarrow$ USD-HKD & 7.75555 & 7.75615 \\
\hline
\end{tabular}

Figure 1: The Forex table of exchange rates

Transactions has no minimum or maximum duration. The minimum duration for certain revaluations is fixed for example by some brokers to 3 minutes.

There is no official exchange rate, also because it would be impossible to have it synchronized in an identical manner in all parts 
of the world over a period of one second. So this table is in principle and by contract free to vary tick by tick for each broker, although the variations from broker to broker are very small.

Fluctuations in interest rates are determined by "market makers". They are mostly national banks and large private banks. The interbank market is deregulated and decentralized and is the core level of Forex. The trading platforms of rates between banks are technological devices made mutually between two banks from time to time or through brokerage platforms such as "Electronic Brokering Services" (EBS) or "Reuters Dealing 3000 Matching". Such platforms are the two major competitors in this sector and together realize a circuit of about a thousand of banks.

You can make an analogy between the Internet and Forex. The Internet has no central core, although it finds its cultural and technology base in the U.S., as well as the currency traded for more than $80 \%$ in the FX market is the U.S. Dollar, which therefore constitutes a collection of technical standards, protocols and operational procedures which have established "de facto" as reference points. Like the Internet, which is not the only way to exchange data and information but has had the upper hand on proprietary protocols, there are several trading markets alternative to Forex, although not very widespread.

\section{A Bit of History}

Trade is an essential activity in social and productive life and has existed since man was able to find an alternative to bartering. But the introduction of technological means of money, through its expression in coin or currency has obviously led to other problems, such as the need of exchange between currencies. The same coins or currency are the subject of considerable trade. And so was born the finance.

In the modern world, the birth of the currency market is identified with the definition of the Gold Exchange Standard in 1876. In fact, there have been several such standards over millennia, including those of bimetallic type (silver and gold). They have been repeatedly taken up and abandoned according to the looming liquidity needs, in particular at economic cycles and war, but the agreement began in the late 19th century is one that has started to actually put a little order among the various modes of exchange between the currencies and coins of modern countries.

After the two Great World Wars, the new stability has idealized the possibility of creating a strong agreement between the convertibility of currencies and gold held. This brings us to the Bretton Woods agreements of 1944, which set the gold convertibility of the dollar at $\$ 35$ per ounce with a freedom of devaluation of $10 \%$. According to such agreements a U.S. banknote was a real title of possession of a quantity of gold.

Within a few years, however, this system proved too hard to meet U.S. large projects in Vietnam war so, in 1971, was formalized a unilateral decision to leave the choice of the dollar as coin and to embrace the choice of the dollar as currency. In these terms, dollar became a real "commodity", a bearer instrument whose value depends on the reliability of convertibility in an usable value like gold or oil from the issuing entity. So goes the value quoted. From day to day. Every second, from tick to tick.

It is very important to consider that the very next year, in 1972, Professor Tobin at Princeton University in his memorable reading notes that the vast majority of money flows across borders of different countries are not related to the purchase of goods, but to pure speculation. These large capital movements cause large fluctuations in exchange rates, for which the value of a currency, or the wealth of a nation, is no more tied to its ability to produce quality and quantity of goods.

Tobin also notes that the percentage of money exchanged for financial speculation and money exchanged for commercial operations is over $90 \%$. Tobin also considers that such speculation is profitable even for very small percentage of profit, which assumes that a slight tax on financial transactions does not penalize trade, which normally has a much greater percentage of profit, but only financial transactions. Tobin does not make a precise calculation at that time but speaks of an indicative value, less than $1 \%$, "Let's say $0.5 \%$." The subject is much debated and it is still considered there are more disadvantages than advantages brought by this methodology. Let's keep in mind the rationale for the existence of currency and coins as an alternative to barter and the complications that a technical solution involves.

In fact, the foreign exchange market exists and the technology has other solutions and other problems [4]. In particular, in 1981 started marketing to great audience of the first desktop personal computer by IBM and modem to connect to computer networks via the telephone line from the company Hayes. In this way anyone from any part of the modern world can technically have instant access not only to data conversion, but also can operate in buying and selling. Since 2005, version 4 of the transaction software Meta-trader established a standard also as regards the programmability in an automatic way by the end user.

\section{Forex Trading and Official Values}

The actual exchange values between international currencies are determined by national central banks in compliance with the various agreements made from time to time at meetings of representatives of major international economies (G8, G10, etc.) and under the guidance of the International Monetary Fund. The trend of Forex strongly influences the table of currencies' exchange values produced daily by the IMF. This table is expressed on the basis of a common exchange value said Special Drawing Rights (SDRs), which is a sort of "virtual currency". Consequently, the Forex periodically aligns with the above said actual trading values.

This "virtual currency", since the G10 in December 1971, when the Smithsonian Agreement was signed, replaced the gold standard established by the agreements known as "Bretton Woods" in July 1944. It also allowed the fluctuation of exchange rates, used for devalue the dollar and stem the gold needed until then for the expenses related primarily to the conflict between the U.S. and Vietnam. The institutions created at Bretton Woods survived the fall of the gold standard, while reviewing their objectives. The International Monetary Fund and World Bank are still in business, while the GATT was replaced in 1995 by the WTO (World Trade Organization).

\section{Performance of Forex}

After describing briefly what it is or what is known as Forex, let's see what are its "dynamic" characteristics, i.e. what happens within it $[5,6]$. From the assumptions made, it appears that in the first Forex moves a high amount of money. The amount of money exchanged in a single day in the Forex (3,000 billion dollars in 2007) is equivalent to twice the GDP of a full year of an economic power like Italy or 
Canada, or equal to twenty times the volume of trade the daily NYSE New York Stock Exchange.

Another aspect of Forex that at first glance may not have been considered by the reader is that the Forex trading regards immediate liquid assets, i.e. monetary currencies themselves [7]. This lets you know immediately and exactly the value of your "inventory". In theory even basic commodities such as gold or oil have a so immediate convertibility.

The Forex is then shown as the market closest to the ideal of perfect competition inasmuch the big movements at stake make impossible its manipulation by any entity or large national bank, nor is it equally easy to anticipate the trends in the basis of undisclosed information (insider trading).

The main features of Forex are therefore:

- Large amounts of exchange lots

- Lots consist of cash

- Greater market volatility

- Worldwide geographical dispersion

- Continuity of operations: 24 hours a day except weekends (OTC)

- Open to small investors through the leverage system (see below)

- Major investment results with small changes in the market due to the lever

- Tax-free profit (no longer in Italy)

- No commissions (not always)

\section{Forex in Practice}

You can access Forex by opening an account from a broker. This operation is typically done online and you have to present a special documentation which must match the collection and withdrawal banking data in compliance with anti-money laundering regulations. Among the offers to end users, brokers offer a Web access through special programs ("Terminal", see Figure 2) for PC, tablet or smartphone.

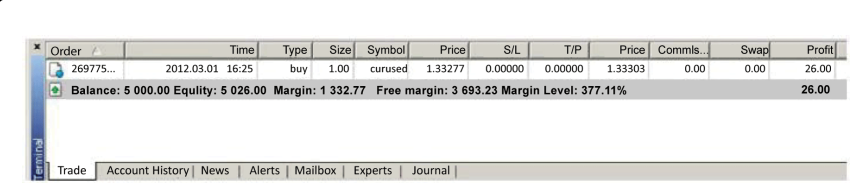

Figure 2: An example of Terminal program

Less evolved brokers present exchange rates with an accuracy of 4 decimal places, while it is now standard to operate with 5-digit rates. This numbering as regards cross currency with the Yen becomes respectively of 2 and 3 decimal places. With the 4 -digit brokers you maintain the correspondence between pip earned (see below) and listing of cross currency, while with 5 decimal place brokers you should keep in mind that working with "mini" pips. Many automated trading programs, while working on the platform of common terminal, can not take into account this difference and should be adapted to the specific broker.

Pip stands for "percentage in point" (Figure 3) and in the beginning, when in the Forex it was active only the 4-digit precision, it was the minimum nonzero fluctuation that a cross currency could suffer. Pip is still of 4 digits for the official conversion rates.
Many brokers offer ECN type account that enables more immediate, direct market, rather than mediated by their internal platform, at the "cost" of having to repeatedly define boundary conditions such as Take Profit or Stop Loss. Operating on an ECN account can cause malfunctions to automatic programs that does not allow for this.

As part of the Forex brokers offer investors an instrument called leverage or margin. Leverage consists in the "multiplication" of the effective investment by a factor that ranges from $2 \times$ to $100 \times$ or even $500 \times$. This lever amplifies further the volatility and liquidity features of the Forex allowing small amounts to have consistent results in a very short time [8].

Forex can be approached for various degrees of risk attitude. All brokers offer a platform for working in simulated mode; then you can start from a "micro" prepaid account, of at least $\$ 100$, and upgrade to accounts reserved to investors operating positions with at least 3 lots (whose margin is at least $\$ 3,000$ with a leverage of 100 ). "Micro" investors are instead given the opportunity of working with cents of a lot (microlots) and in some cases thousandths of a lot (nanolots). Opening a position of $\$ 10$ should not be thought of as a negligible movement, since you have to take account of the leverage, typically set just to 100 which moves in fact a substantial amount of money.

Many brokers offer different types of account. Accounts dedicated to customers who want little risk or are just beginners allow mini or micro lots, but they can hide operating limits such as maximum number of lots open, or a limit on the volume of each transaction.

So in the Forex you work with "prepaid" accounts. The amount of capital accounted for is called "Balance", while the total amount of earnings and/or loss of open positions is called "Equity". It should be noted that the cash actually available in a given instant corresponds to Equity and not to the recorded Balance.

Suppose you have an account with a recorded Balance of $\$ 1,000$, a leverage of 100 and an open position of one tenth of lot ( 0.10 lots correspond to a Margin of $\$ 10$ with a leverage of 100)with a loss of $\$ 300$.

Clearly we are confident that the market will be benevolent and that this position will turn in our favor by making a profit. But if we need to close the account, this would lead to recording a loss of $\$ 300$, so the recorded Balance would be $\$ 700$, much as we can order as a transfer in our bank account.

Another important variable of the operational account to consider is the "Free Margin". It corresponds to the Equivalent less the Margin (which corresponds to the amount of committed capital for ongoing operations including results of current open operations) and represents the cash available for opening new positions.

We already said that the minimum fluctuation for an exchange pair is called "pip" (Figure 3). Normally, a pip is one ten-thousandth of an exchange rate. For example, if the EUR/USD currency pair is currently at 1.3473 , rising to 1.3493 gives a fluctuation of 20 pips (upward). Such a fluctuation in the ordinary moments takes a few hours. In times of maximum turbulence fluctuations can also have hundreds of pips in a few minutes. 


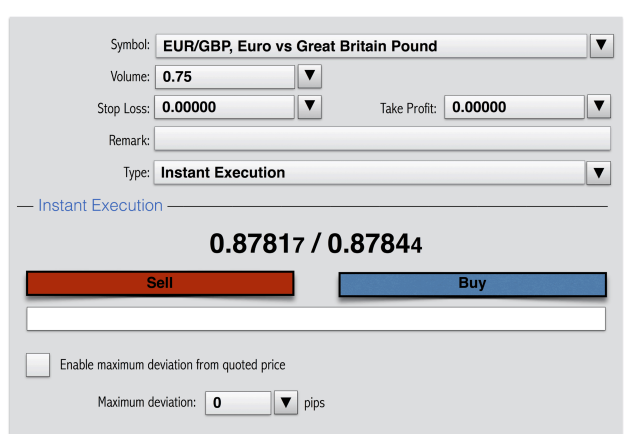

Figure 3: An example of "pip"

An open position of half a lot of a dollar account with a leverage of $100 \times$, following a 20 pip move has yielded or did lose a dollar amount equal to: 20 (pips) / 10,000 (pip ratio) $\times 0.5$ (half lot) $\times 1,000$ (lot ratio) $\times 100$ (leverage) $=\$ 100$.

In fact, the broker charges a fork between the buy and sell rates, the so-called spread, expressed in pips. In some cases it also adds a swap cost if the operation lasts more than 24 hours and is renewed at 21:00. The swap is an interest cost, and is related to the need for the broker to make the rollover, i.e. terminate the trading day for a few minutes a day to renew the contracts. This is done to prevent the physical transfer of paper money corresponding to the currencies bought or sold, but the Inland Revenue in Italy considers this loophole of no value, thus considering taxable the Forex operations. Note that the example shown expresses a genuine opportunity to multiply by 10 a fraction of the capital over a few hours. Obviously it can also happen in reverse, i.e. a counter-market position open for half a lot lowers the cash available for other exchanges (equity), until drying up completely the deposited amount in the account. In certain situations you can have more liquidity than prepaid.

It is generally known that in the Forex there are no commissions. This is usually true, because brokers usually only profit from the buy/ sell prices' fork, i.e. on the spread. The competition led to extremely lower these spreads, until you have brokers who advertise 1-pip spreads for major crosses as EUR/USD or GBP/USD. In fact, brokers are appearing that offer even spread of 0.2 pips, but require a fee between $\$ 3$ and $\$ 4$ per lot traded.

Many brokers offer included with the account, under certain conditions (at very low cost or even free of charge), the VPS (Virtual Private Server) service that allows users to access the terminal program via a remote protocol, i.e. to operate an automated Expert Advisor 24 hours a day without the need for the trader to leave a PC always on at home or office.

\section{Charts}

After selecting a broker and opening an account, it is important to know the operating interface of the program and control its functions. The information previously provided allows you to correctly interpret the pane that shows the accounting data, and the one presenting the tick-to-tick performance of cross-currency conversion rates. It's time to describe the window that represents the historical performance of each cross currency, i.e. the plot window.
Initially one might imagine that a "signal", i.e. a value (onedimensional in this case) over time would be sufficiently plotted through a broken line (Figure 4).

In fact, since data points are "sampled" over a time interval (H1, which is an hour in the image presented), they do not give an accurate information of what happened during the hour (i.e. the time interval) considered. So "bar" or "candle" representations have become so popular (Figures 5 and 6). For each time interval are reported in a very intuitive way the values:

$$
\begin{aligned}
& \text { - Maximum } \\
& \text { - } \text { Openininum } \\
& \text { - Closing } \\
& \text { - Direction (upward or downward) }
\end{aligned}
$$

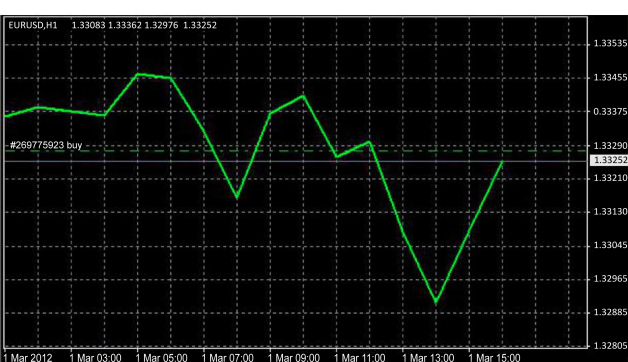

Figure 4: A Forex plot

Charts are normally available for periods of 1 minute (M1), 5 minutes (5M), 15 minutes (15M), 30 minutes (30M), 1 hour (H1), 4 hours (H4), 1 day (1D), 1 week (1W), 1 month (MN). Normally we use H1 charts, but also M30 and M15.

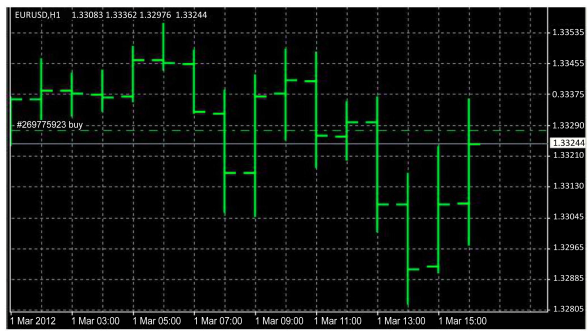

Figure 5: A bar chart

On the chart it is possible to draw indicators (Figure 7) or mathematical formulas that represent an interpretation of the past exchange rate for the foreseeable future and suggest whether it is appropriate to buy rather than sell depending on the intersection between the current signal and the indicator. 


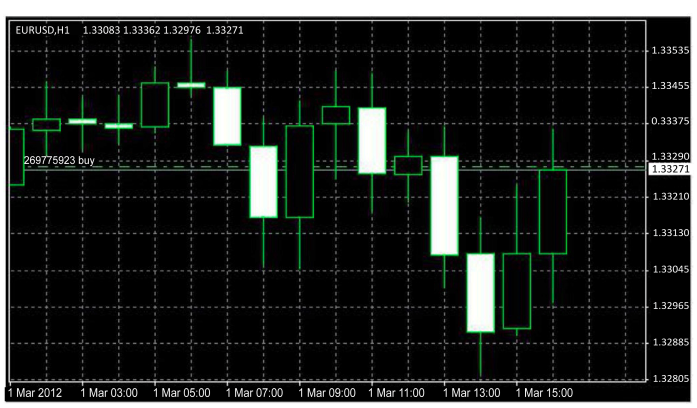

Figure 6: A candlestick chart

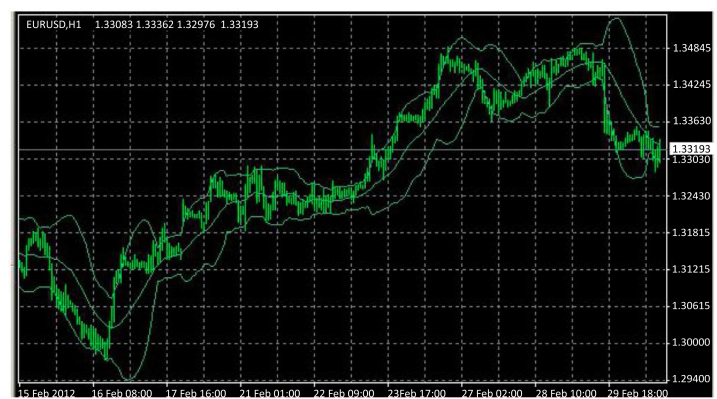

Figure 7: A chart with indicators

\section{Trading Orders}

Trading orders may be primarily of two types:

- Instant execution

- Pending orders.

The opening of an instant execution order requires at least the following three data:

- Symbol of the pair of currencies on which you want to invest

- Volume, i.e. the amount of lots invested

Type of transaction: buy or sell, also known as long or short and the following optional data:

- Stop loss

- Take profit

- Slippage

- Comment

- Magic Number (only for open positions through Expert Advisor or Automated Trading Robot)

The Stop Loss is the value of the exchange rate at which you consider the order should be terminated automatically by the broker. Normally the closure should be performed manually, or should be made by automatic trading program. But it is always a good practice to define a value of Stop Loss, as for example an Internet connection could be no longer available at a market turbulence and a single operation could drain the entire value of the account if no longer monitored.
It is always a good standard to define also the Take Profit from the outset, as it is very important to know at what point to consider sufficient the fluctuation in our favor. Too low a value corresponds to a loss of income, a too high value may actually correspond to a loss as if it is not reached, the value could reverse direction.

As we anticipated, with ECN type broker it is necessary to define these two values after the opening. Terminal programs also allow, for already open positions, a minimum automation function corresponding to the "Trailing Stop", i.e. to a system of "ratchet" Stop Loss with a minimum interval of 15 pips. The Trailing Stop can lead to safe losses (never over fixed points) as well optimized gains, as it should be used only if you know what you're doing. One should not forget that Forex is a real market, so for example to the opening of a selling order the broker matches one or more purchase orders. It is true that automation and sophistication of computer tools show it as a form of gambling, but in fact an order must be drawn from the underlying platform, and this may take some time.

It is thus in this way that the Slippage should be defined, that is the acceptable deviation in pips between we place the order and the listing of the cross when the order is executed. Orders below 3 lots do not involve problems of "placement", but for larger lots the time lapse between the moment in which the order is required and the time at which it is run can be substantial, and providing a generous slippage can lead to lower profits but more execution speed due to the greater probability of being executed in the first instance.

The Comment is optional and serves as a reminder to the investor.

The Magic Number is instead a unique number arbitrarily chosen by the programmer to identify the order made by the program itself, as it should operate alternately on manual orders or on orders from other programs.

Pending, or deferred, orders are an easy way of automation offered by terminal programs and let the broker activate an order automatically at the occurrence of certain market conditions. This allows a simplification of the operations of "Forex sitting"(The activity of monitoring the performance of charts and trading; it is a playful expression in which the trader is identified in some cases with a babysitter). Pending orders can be of four types:

\section{- Buy Stop}

- Sell Stop

- Buy Limit

- Sell Limit

The Buy Stop and Sell Limit plan the actual purchase or sale order under the condition that the exchange rate has risen to a certain level. In practice it is ordered to the broker to open automatically the order only if the value of the cross, while rising, reaches a predetermined value.

The Buy Limit and Sell Stop instead relate to an alleged downturn of a cross.

A pending order, therefore, requires the same data of an immediate order: Symbol, Volume, type (Buy Stop, Sell Stop, Buy Limit, Sell Limit), plus the value of activation of the cross ("at price") and the same optional values: Stop Loss, Take Profit, Slippage, Commentary, Magic Number, plus the value of the option expiration date and time. In fact, within a few hours it does not make sense to take up a pending order. It turns out in a stalemate: no charges are made because the order has never taken its course. 
The history of trades carried out under an account is called "statements list".

\section{Speculative Approaches}

In order to decide on what positions to open and why you need information. These data may be "raw" (political and economic updates, charts and graphs about the market) or in a form readily usable, that is "signals". In fact, the signals come from two types of speculative approaches, as in the stock market:

- Fundamental Analysis

- Technical Analysis

The basic approach involves the purchase and sale are dictated by considerations derived from the analysis of macro and micro economic data, and from reports publicly submitted by national and financial bodies on economic trend of the nations involved with currencies in question.

For example, every three months in the U.S. the data on NFP (NonFarm Payroll) are taken, or salaries of employees to non-agricultural activities. These reports provide information deemed very important for the development of trade and at these publications currency follow unpredictable and consistent fluctuations.

The basic approach is characteristic of the investors operating in the long term or on operations lasting up to weeks. Technical analysis is instead based solely on the analysis of charts and can be automated. It clearly fails at "calendar" or unexpected events. The technical analysis is suitable for investors with operations lasting up to one day (scalpers). In any case, any trading strategy must not only be based on "when to open" an operation but must also consider "when to close" it. This condition can be considered more important than the simple opening strategy.

An approach to a strategy must be clear and well defined. The penalty shall be a condition because emotion can easily take over when the perception of loss is greater than the actual variation in percentage of long-term budget. It is in this context that the automated approach, certainly more expensive initially, offers a more robust support as simulated with historical data with different operating parameters but also free from emotion.

\section{Indicators}

Whether you follow a basic or technical approach, a manual or an automated approach, indicators are needed. The indicators draw data only on the past, but allow us to hypothesize the future. There are six main types of indicators:

- Trend indicators: moving averages, MACD

- Volatility indicators: Bollinger bands

- Momentum indicators (strength/weakness of the trend): stochastic

- Volume indicators

- Cycle indicators (recurrences): Elliott waves, Fibonacci

- Bill Williams indicators: alligators, fractals

One indicator alone is not sufficient. An indicator may suggest the best time to open a position or vice versa, the less suitable. Learning to use a marker or automatically verifying a strategy based on an indicator is very instructive.
From web pages free of charge up to personalized SMSes you can subscribe to notification services operating on the Internet.

\section{Trading Strategies}

\section{Hedging and correlation}

In many "macro" trading strategies, but also in many simple strategies are inherent mechanisms of damping losses. These are balancing systems, also known as hedge. In practice, for each open position it is considered to be another similar but in contrast so that can be reached in each case a target gain even in adverse market conditions. This result in the Forex is generally obtained through the adoption of multi-cross trading strategies, using appropriate correlation tables frequently updated. The limitation inherent in the correlation and in hedging is that, if it is true that you never lose entirely, it is also true that you will never gain totally. If a strategy is valid, it is sufficient to follow it, otherwise it is the case to follow another.

\section{Money management}

Each strategy should not simply identify the moment of opening and closing a position, but must also know how to show "how much" to invest in this transaction. This amount (of course expressed in lots) may be a function of Equity, Balance and also of the "strength" with which the open position is considered valid.

\section{Automated Trading}

Automated trading systems are called (EAs) or more briefly Robots. Identically to each "manual" strategy, the algorithm at the base of each robot consists of a section that deals with the strategy and one that deals with the Money Management. As already noted, the advantages of an approach to automatic trading are the following:

\section{- Lack of emotion}

- Absence of human supervision

- Can also be used by beginners (with a grain of salt)

- Ability to optimize the parameters through the back-testing

While the first two points are intuitively understandable, the other two points must be detailed. First, the use of an Expert Advisor is very rarely free from options, especially as regards the adaptation to the broker and as regards the money management. As a good Robot can be purchased at the price of a few tens of euros and as it may be well documented, there are always some things you can miss as to its development. It is appropriate at this point to always refer to a community to have the information necessary, or is more appropriate to refer to the guidance of an expert.

\section{Back-testing}

The ability to perform back-testing is the fundamental reason why an approach to trading based on an Expert Advisor is enriched with reliability and overview. Through back-testing it is possible to develop all the variables involved in an operational context, from input to output strategy, to money management parameters. You can do several simulations, to find what are the parameters that put the mechanism working at peak efficiency.

However, there are three major limitations of back-testing: 
- Quality of historical data

- Quality of the simulation algorithm

- Applicability of history to future events

First, it is extremely difficult to use historical data quality related to the broker actually used. Brokers offering quality historical data are very few in front of hundreds of brokers operating in the world. Using historical data from one of these brokers may give data inconsistent with the broker used. Often the data sets provided contain several time "holes" or in different points contain significant "planed" oscillations.

Secondly, the simulation algorithm, even with accurate historical data on the cross, ignores the following boundary conditions that in the real world greatly influence a strategy:

- Variation in the spread

- Daylight saving time bias

- Market availability and consequent slippage

The simulation subroutine therefore presents in its report a reliability index of the simulation performed expressed as a percentage. Even having a simulation with a reliability index of $99 \%$ over the ten years just passed, not far from clear that a new situation will not occur in the future and put in a crisis an apparently robust trading algorithm. What did not happen in the past could just happen in the next few hours.

\section{Forward testing}

The forward testing is an oxymoron. In fact, you should talk about testing. But the term is often used, due to its opposition to the term back-testing. We consider the forward testing as the testing phase later than that of back-testing. Obviously it is much slower, but gives more information than the true back-testing.

The forward testing with a demo account has still room for unreliability with respect to a real test (investment). This is related to the fact that the trading conditions simulated in a demo account can be different from those of a real account. For example, the spread is very low or there are no limits on the volumes exchanged. Even the price can vary. Sure, the slippage is zero, so there are no delays in the execution of an order, something that cannot happen in an order with a real account.

\section{Arbitrage}

A particular type and theoretically illegal automated trading is based on arbitrage. Arbitrage is the basis of trade. What is cheap and abundantly available somewhere is highly sought somewhere else. Merchants loaded their ships in the East with spices, tea, carpets, fabrics and sold them in the West, then departing for the East with their holds full of metallurgical products.

In Forex, between a broker and another there may be differences in price on the same cross. This happens for a few pips and for a short time. But with care you can get great profits. With a suitably programmed Expert Advisor you can implement the following algorithm.

It should be noted that this strategy is expressly prohibited under all conditions of membership to any broker, but it is impossible for the broker to show that this activity may have been in place since the competitor broker's trading data should also be available.

\section{The commercial and open-source landscape of EAs}

As in the world of commercial software and operating systems, also in the field of EAs there are robots developed with open source and closed source software. Even in this case the software distributed free of charge should ensure wider dissemination and greater operational documentation at various forums, at the expense of a lower finishing and professional support. It easily happens to run into paid programs well publicized but of poor quality.

\footnotetext{
1. Consider two terminals simultaneously working on two different brokers.

2. On one terminal you open up a position for sale on a particular cross. On the other for purchase, of equal volume, for example a lot.

3. For a while, since the cross are identically quoted, and varying the price, one terminal gains and the other loses the same amount. In fact, you lose a little more, because of the spread.

4. At some point, it can happen that one of the two brokers evaluates the cross in a different way from the other. This may be due to a slowdown in its connection to the "core" brokers, or to a settlement on its brokering strategy which may consider an optimization of the transactions of its customers who have a market sentiment different from that of the rest of the world. For example, consider the case of one American or European broker and the other Asian.

5. This listing difference may result in a profit or loss balance between the two operations in the two accounts.

6. When the divergence thus provides a satisfactory margin, the two positions are closed. One account will have lost something and the other will have gained something, but the profitable account has earned more than the other has lost.

7. The cycle is restarted.
}

The commercial and open-source landscape of EAs.

As for generic software, the EAs are also copy protected and you should consider if the copy protection system is not too invasive. Since reverse engineering based on decompilation is very simple, there are three systems with which an EA is otherwise protected from unauthorized copying:

- Moving the operating code in a DLL

- Moving the algorithms at a central server, thus the EA simply works as a data collector and executor of operations

- EAs as simple executors of signals delivered from remote

\section{Families of expert advisors}

EAs operating in resident mode in the traders' computer therefore operate on the basis of the historical data processing of the cross, that is according to a technical approach. The most common algorithms underlying the EA are:

- Martingale

- Gann Pyramid

- Grid

- Resistance and Support

More sophisticated implementations are based on the following algorithms:

- Fibonacci retracement

- Pattern

- Elliot waves

or they integrate a simple strategy with one of these indicators. 
Page 8 of 9

\section{(Historical) Rating of a Strategy}

Whether it's a back-testing, whether you wish to evaluate the operating performance of an actual operating trading account, the parameters to take into consideration are the following:

- Daily/monthly gain

- Drawdown (maximum, percentage)

- Duration of transactions

- Successful consecutive trades (mean and absolute)

- Z-score (probability of ruin)

- Distribution of operations over the time of day and days of the week

- Doubling (tripling) time

Of all these parameters, of course after the measurement of absolute gain and divided by period, the most important is the drawdown. It measures the risk that you went to meet during the operations. Suppose you are considering an account that, in the simulation or in reality, in a month has done 100 operations. Of these operations, 99 have been exactly well-aimed, i.e. for example when the buy position has been open the index started to rise until the attainment of the closure for take profit. In one case, however, for a transaction stop loss was not used, or you used an excessive stop loss, or even your strategy does not include stop loss. In this case the order has gone through a phase in which the transaction was at a loss, then recovered and led to profit.

Suppose that in the worst moment this sole operation was at a loss of $\$ 100$ to an account with a balance of $\$ 1000$. In this case it is said that the adopted strategy is characterized by a drawdown (maximum, percentage) of $10 \%$. Strategies considered valid have a drawdown of less than $30 \%$. In fact, if you think about the fact that an account with a broker is prepaid you understand that in fact of the paid-up capital what actually works is normally only a small part. The rest serves as a reserve for dangerous times.

With that in mind and considering that the account with a broker is not guaranteed like a bank account, it is important to evaluate the doubling time of the capital initially paid. After the doubling time, you may consider to recover the entire amount originally paid to operate safely. But you might risk all gain as if you had not worked at all until then.

Then we must consider the tripling time (which of course is only slightly higher) taking into account the capitalization of earnings, to begin to consider the beginning of operating as an income producer and revenue from the Forex system considered.

The rate of profit is the maximum guarantee in the financial field. An investment that pays $20 \%$ per month (normal for a professional trader), has a doubling time of 4 months and 6 months of tripling time and therefore needs no other long-term guarantees. In the more realistic case of a return of $10 \%$ per month, times are 7 and 11 months respectively. Provided that in the meantime you did not lose all capital. Ordinary investments for the general public that advertise the annual returns of 5\% have a doubling time of 15 years and a tripling in 22 years time, and they need guarantees of national funds that should take account of supervening conditions and financial policies significantly changed.

\section{Social Forex}

Many websites offer data exchange on performance of their Forex accounts, even in real time, representing themselves as "Web Apps" that allow you to have a very thorough overview on operational statistics in absolute and relative sense to other users.

Starting from their published data thus becomes possible for popular traders to present themselves as sellers of Forex signals.

\section{How a Broker Earns}

A broker earns on the spread, so his goal is to maximize transactions per time unit. Brokers agree not to drain the accounts of their traders because they would make no more transactions. To this end, they encourage the use of quality EAs and customer acquisition through traders appropriately identified as reliable. Figure of Introducing Broker is not rigidly regulated as that of the financial advisor, but is configured as a simple "presenter" of the technical system, as the customer himself will open an account directly with the broker and make his choices in an autonomous way. To the Introducing Broker is paid a small percentage on the spread moved from introduced "friends", so he too has the advantage for newcomers to succeed.

There are other promotions conducted by the broker to that effect. For example, some recognize at month end bonuses based on volume of lots moved, regardless of the outcome of gain or loss of transactions. Others recognize, at the beginning of the month, a bonus that is then paid at the end of month if a certain volume of trade (typically very high) has been maintained.

Many brokers also offer the opportunity for more experienced traders to offer to other investors through accounts like PAMM (Percent Allocation Management Module), i.e. accounts where individual third parties may deposit funds and participate in the gains and losses.

\section{Conclusions}

In this paper we analyzed the issues related to computer applications in finance. In particular, we dealt with the particular financial market named Forex and how computational tools can cope with the forecasting problem [9]. In fact, computing methods have become very important in making (financial) predictions and for solving business problems, where they have proven their advantages over statistical and other traditional methods.

In spite of many benefits deriving from the computational tools for trading automation, there are also limitations that should be investigated, such as the relevance of the results, and the "best" mathematical model [10] for the certain problems.

In particular this is true for Forex, an incredibly vast market but nonetheless open to small investors. Its learning curve has a very small starting step, but nevertheless is very "long". Risk can be individually profiled deciding the capital to invest (which in early stage, next to a proper apprenticeship, must never be more than a couple of months of own income because the projected profits are substantial, but they correspond to a considerable risk). In no way it can be however guaranteed that past performance is occurring in the future, and that the forecasts should occur. 
Citation: Crescenzio Gallo (2014) The Forex Market in Practice: A Computing Approach for Automated Trading Strategies. Int J Econ and Manage Sci 3: 169. doi:10.4172/2162-6359.1000169

Page 9 of 9

\section{References}

1. Abraham A (2002) Analysis of hybrid soft and hard computing techniques for forex monitoring systems, Proceedings of the 2002 IEEE International Conference on Fuzzy Systems, Honolulu, HI, USA, pp. 1616-1622, ISBN 0-7803-7280-8.

2. Jorion P, Sweeney R (1996) Mean Reversion in Real Exchange Rates: Evidence and Implications, in Neural Networks, vol. 2.

3. Baestaens DE, Van Den Bergh WM, Wood D (1994) Neural Network Solutions for Trading in Financial Markets, Financial Times, Pitman Publishing, London.

4. Kattan A (2011) Artificial Neural Network Training and Software Implementation Techniques, Nova Science Publishers, ISBN 1611229901.

5. Bredin D, Hyde S (2004) FOREX Risk: Measurement and Evaluation Using Value-at-Risk, Journal of Business Finance \& Accounting, Wiley, 31(9-10):1389-1417.
6. Yaoa J, Lim Tanb C (2000) A case study on using neural networks to perform technical forecasting of Forex, Neurocomputing, 34(1-4):79-98.

7. Moorea MJ, Rocheb MJ (2002) Less of a puzzle: A new look at the forward Forex market, Journal of International Economics, 58(2):387411.

8. Azoff ME (1994) Neural Network Time Series Forecasting of Financial Markets, John Wiley \& Sons, New York.

9. Gately E (1995) Neural Networks for Financial Forecasting, John Wiley \& Sons, New York.

10. Wai Wong K, Sumudu B, Mendis U, Bouzerdoum A eds (2011) Neural Information Processing: Models and Applications, Springer, ISBN 3642175333. 